endourológicas si se sospecha una neoformación como posible causante de la hematuria ${ }^{2,7,8}$.

Pensamos que ante una hematuria en el niño, al igual que en el adulto, la ecografía del tracto urinario debe ser la primera prueba de imagen por realizar para descartar litiasis, defectos morfológicos o neoformaciones. Ante una imagen tumoral menor o igual a $3 \mathrm{~cm}$, la exploración endoscópica, y la resección para su confirmación diagnóstica en el mismo acto, es la opción terapéutica idónea para evitar con esto una anestesia posterior. Puede ser utilizada tanto la electrocoagulación como la fulguración con láser ${ }^{1,2,7,8}$.

B I B L I O G R A F Í A

1. Fernándes ET, Manivel JC, Reinberg Y. Hematuria in a newborn infant caused by bladder hemangioma. Urology. 1996;47:412-5.

2. Cheng L, Nascimento AG, Neumann RM, Nehra A, Cheville JC, Ramnani DM, et al. Hemangioma of the urinary bladder. Cancer. 1999;86:497-504.

3. Martin Martín S, Muller Arteaga C, Gonzalo Rodríguez V, García Lagarto E, Egea Camacho J, Fernández del Busto E. Hemangioma vesical. Actas Urol Esp. 2007;31:1172-4.
4. Ikeda T, Shimamoto K, Tanji N, Ohoka H, Nishio S, Yokohama M, et al. Cavernous hemangioma of the urinary bladder in an 8-yearold child. Int J Urol. 2004;11:429-31.

5. Greenfield SP, Williot P, Kaplan D. Gross hematuria in children: A ten year review. Urology. 2007;69:166-9.

6. Domínguez Hinarejos C, Bonillo García MA, Alapont Alacreo JM, Serrano Durbá A, Estornell Moragues F, García Ibarra F. Valoración de la uretrorragia en el niño. Actas Urol Esp. 2007;31:29-32.

7. Bromage SJ, Chan L, Collins RL. Ultrasound guided location and resection of a suburothelial cavernous hemangioma of the bladder. Br J Radiol. 2007;80:e113-4.

8. Serrano A, Domínguez C. Transitional cell carcinoma of the bladder in children. Scand J Urol Nephrol. 1999;33:73-6.

J.A. March Villalba*, C. Domínguez Hinarejos, A. Serrano Durbá y F. García Ibarra

Servicio de Urología, Departamento de Urología Pediátrica, Hospital Universitario La Fe, Valencia, España

*Autor para correspondencia.

Correo electrónico: joseantoniomarch@hotmail.com

(J.A. March Villalba).

\title{
Nefroma multilocular quístico. Nuevo caso y revisión de la literatura médica reciente
}

\section{Cystic nephroma. Case report and overview of recent literature}

\section{Sr. Director:}

Presentamos el caso de una mujer de 52 años de edad, sin antecedentes familiares o personales de interés, salvo perimenopausia. En noviembre de 2007 consulta por molestias difusas y leves en el hemiabdomen izquierdo, con pirosis y sensación de distensión abdominal alta. Se realiza una ecografía abdominal, que revela una masa retroperitoneal mixta, solidoquística, de $20 \times 13 \times 16 \mathrm{~cm}$, que contacta con la cola del páncreas y desplaza el riñón izquierdo hacia atrás. Análisis de sangre y de orina dentro de la normalidad. Radiografía de tórax normal. Tomografía computarizada: masa renal izquierda de $13 \times 19 \times 13 \mathrm{~cm}$, multiquística, bien delimitada y con discreta calcificación lineal periférica focal. Múltiples septos realzantes. No presenta adenopatías ni lesiones sugestivas de metástasis. El resto del abdomen sin datos de interés (fig. 1).

Se realiza nefrectomía simple izquierda (26-11-2007) con la sospecha de probable nefroma quístico (CN) y menos probablemente carcinoma renal quístico. Postoperatorio sin incidencias.

La pieza de nefrectomía izquierda, de $2.490 \mathrm{~g}$, muestra una lesión redondeada que mide $18,5 \times 15 \mathrm{~cm}$, bien delimitada, no encapsulada, que desplaza el parénquima renal normal, del que sólo se identifican dos pequeñas porciones de aspecto normal correspondientes a ambos polos. La lesión tiene aspecto poliquístico, con contenido seroso y de consistencia esponjosa. El estudio histológico (fig. 2) demuestra que los quistes se encuentran revestidos por una única capa de células aplanadas o cuboidales, carentes de atipia. El citoplasma es levemente acidófilo, sin características peculiares. Entre los quistes se aprecia estroma moderadamente celular, formado por células fusiformes, de núcleos ovalados, regulares, igualmente carentes de atipia. En ocasiones, es evidente la diferenciación muscular lisa. No se observan elementos blastematosos. El estudio inmunohistoquímico revela positividad en las células epiteliales para diferentes tipos de citoqueratina (5-6, 7, 34-beta-E12, 18 y 19), pero no para citoqueratina 20. Por su parte, el estroma se tiñe con vimentina, actina de músculo liso $\mathrm{y}$, focalmente, con desmina. Los receptores de estrógenos y progesterona son positivos en la mayor parte de las células estromales. La tinción con CD 10 resultó completamente negativa.

Las diferentes formas de entender el concepto «quístico» (anatomopatológico o radiológico) en las masas renales han llevado a una enorme confusión terminológica y conceptual muy poco clarificadoras, pero acertadamente valoradas en la reciente literatura médica nacional ${ }^{1}$ por lo que el término de 


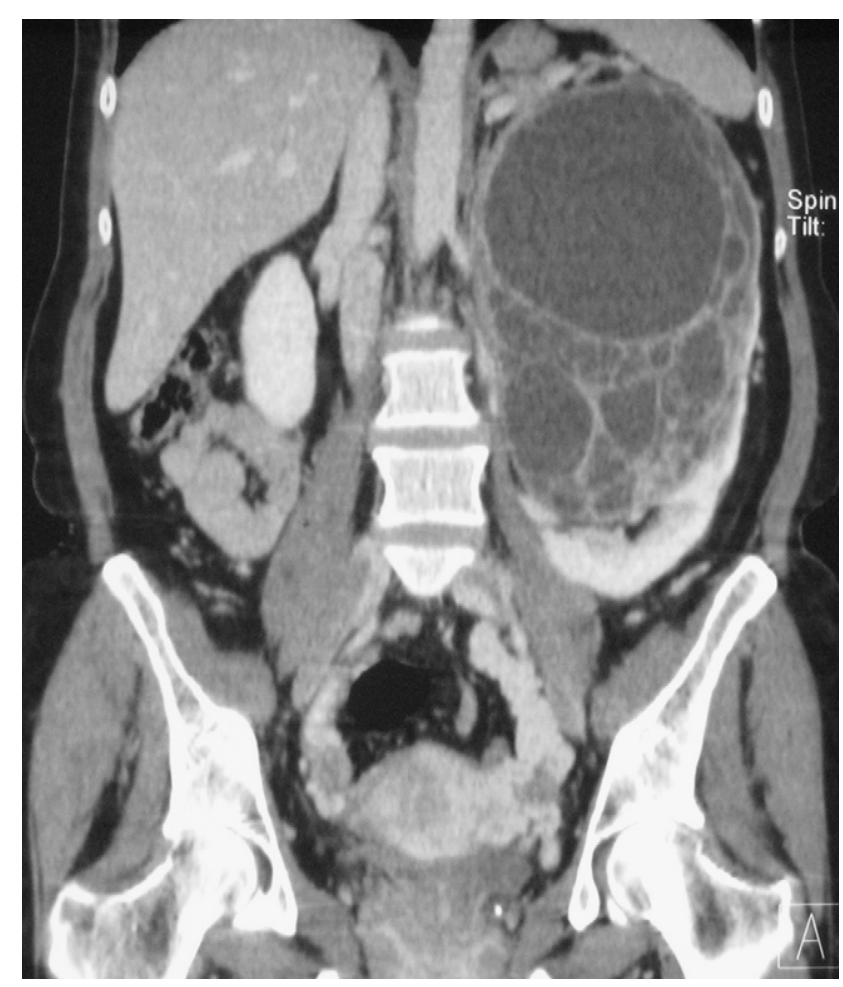

Figura 1 - TC: masa renal izquierda de $13 \times 19 \times 13 \mathrm{~cm}$, multiquística, sin adenopatías ni lesiones sugestivas de metástasis.

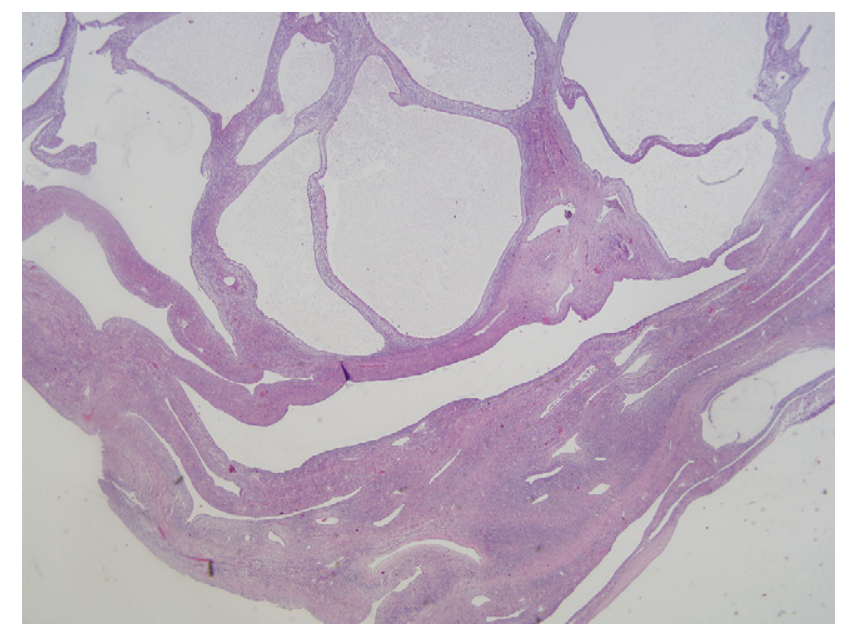

Figura 2 - Estudio histológico. H-E. Quistes revestidos por una única capa de células aplanadas o cuboidales, carentes de atipia.

«tumor renal de configuración quística» parece muy acertado. $\mathrm{Y}$ esto es tanto para los tumores benignos como para los malignos. Muchas de dichas disquisiciones son poco útiles en la práctica y, teniendo en cuenta la relativa poca utilidad de los estudios de imagen, nos vemos obligados en muchos casos a la cirugía diagnóstica y a complejos estudios anatomopatológicos ${ }^{2}$.

En el diagnóstico diferencial del «tumor renal de configuración quística» el abanico de posibilidades es enorme. En la revisión del presente caso pretendemos establecer el nexo entre dos entidades benignas: el nefroma multiquístico y el tumor mixto epitelial y estromal, probablemente la misma entidad. También pretendemos indicar que la coexistencia ocasional de carcinoma renal o de componentes sarcomatosos obliga a un estudio patológico amplio y a un seguimiento estricto de estos pacientes, especialmente en caso de optar por cirugía no radical o control radiológico ${ }^{2,3}$.

Adenoma quístico del riñón fue la primera denominación, a finales del siglo xIx, de una entidad rara, benigna y no hereditaria, con un espectro amplio de hallazgos histológicos, de patogénesis incierta, múltiples denominaciones en la literatura médica y comportamiento bimodal. La terminología es muy controvertida. Éstos son algunos de los sinónimos del CN o multiquístico referidos en la literatura médica: «tumor renal quístico multilocular», «nefroma quístico», «nefroma quístico benigno multilocular», «quiste multilocular», «nefroblastoma poliquístico», «nefroblastoma benigno quístico diferenciado», «nefroblastoma quístico parcialmente diferenciado», "tumor de Wilms poliquístico bien diferenciado», «tumor de Perlman» y «nefroblastoma diferenciado».

El diagnóstico diferencial de las masas renales quísticas varía entre adultos y niños, y puede incluir variantes quísticas de nefroma mesoblástico, carcinoma de células renales, tumor de Wilms, displasia multiquística, linfangiomas, sarcomas, etc 5 .

Desde el punto de vista de la imagen, la ecografía y la TC revelan múltiples lesiones quísticas sin elementos sólidos o nodulares. La mayoría de los tumores se encuadra en los grados III-IV de Bosniack ${ }^{7}$. Tanto la resonancia magnética como la gammagrafía aportan poco al diagnóstico diferencial preciso ${ }^{4}$. Por esto, la cirugía y el estudio anatomopatológico son casi siempre obligados.

Aunque inicialmente el CN y el nefroblastoma quístico parcialmente diferenciado fueron considerados como extremos de un amplio espectro de lesiones, actualmente se tiende a relacionar el CN con el tumor mixto epitelial y estromal del riñón (TMEER), con el que comparte aspectos clínicos y morfológicos ${ }^{3}$. La ausencia de elementos blastematosos separa a ambos del nefroblastoma parcialmente diferenciado o del adulto ${ }^{5}$. Las diferencias entre el CN y el TMEER son sólo cuantitativas en cuanto a la cantidad de estroma presente en ambas lesiones, sin que existan diferencias cualitativas en su composición, a pesar de lo cual siguen siendo consideradas como lesiones diferentes en la última clasificación de la $\mathrm{OMS}^{2,5}$.

A pesar de las dificultades que plantea su clasificación, muestra un aspecto macroscópico y microscópico característico que permite su diagnóstico: se trata de lesiones solitarias, casi siempre unilaterales, multiquísticas, que se presentan habitualmente en mujeres perimenopáusicas ${ }^{3,7}$. El diagnóstico diferencial más relevante es con la variante multiquística del carcinoma de células renales, que se descarta por la ausencia de células claras en el interior de los septos, lo que requiere un estudio exhaustivo desde el punto de vista histológico.

El estudio inmunohistoquímico no es útil para el diagnóstico diferencial, pero la demostración inmunohistoquímica de diferentes tipos de queratinas en el componente epitelial del tumor, como ha sido en nuestro caso, ha sugerido que pueda 
corresponder a una diferenciación hacia el túbulo distal o colector $^{6}$, aunque este dato también ha sido interpretado como que se trata de túbulos atrapados y no de un componente de la neoplasia ${ }^{5}$. La expresión inmunohistoquímica de receptores de estrógenos y progesterona ha sido propuesta como un elemento para separar el TMEER del $\mathrm{CN}^{6}$. Sin embargo, al igual que en otros casos previamente publicados, muestra dicha expresión, lo que demuestra la proximidad morfológica $\mathrm{y}$, probablemente, etiopatogénica entre ambos tumores. Cada vez hay mayores pruebas de que el nefroma multiquístico y el tumor mixto epitelial y estromal son la misma entidad, tanto desde el punto de vista imnunohistoquímico como desde el perfil de expresión genética ${ }^{8}$.

B I B L I O G R A F Í A

1. Sánchez-Martin FM, Pascual Queralt M, Martínez-Rodríguez RH, Algaba Arrea F, Millán Rodríguez F, Palou Redorta J, et al. Componente quístico del cáncer renal: revisión conceptual. Actas Urol Esp. 2008;32:507-16.

2. Eble JN, Sauter G, Epstein JI, Sesterhenn IA. Pathology and genetics of tumours of the urinary system and male genitals organs, in WHO Classification of Tumors. Lyon, France: IARC Press; 2004.

3. Lane BR, Campbell SC, Remer EM, Fergany AF, Williams SB, Novick AC, et al. Adult cystic nephroma and mixed epithelial and stromal tumor of the kidney: Clinical, radiographic, and pathologic characteristics. Urology. 2008;71:1142-8.
4. Silver IMF, Boag AH, Soboleski DA. Multilocular cystic renal tumor: Cystic nephroma. Radiographics. 2008;28:1221-5.

5. Antic T, Perry KT, Harrison K, Zaytsev P, Pins M, Campbell SC, et al. Mixed epithelial and estromal tumor of the kidney and cystic nephroma share overlapping features. Arch Pathol Lab Med. 2006;130:80-5.

6. Mukhopadhyay S, Valente AL, de la Roza G. Cystic nephroma: A histologic and immunohistochemical study of 10 cases. Arch Pathol Lab Med. 2004;128:1404-11.

7. Hora M, Hes O, Michal M, Boudová, Chudacek, Kreuzberg B, et al. Extensively cystic neoplasms in adults (Bosniack Classification II or III). Possible "common" histologic diagnoses: Multilocular cystic renal cell carcinoma, cystic nephroma, and mixed epithelial and stromal tumor of the kidney. International Urology and Nephrology. 2005;37:743-50.

8. Zhou M, Kort E, Hoekstra P, Westphal M, Magi-Galluzzi C, Sercia L, et al. Adult cystic nephroma and mixed epithelial and stromal tumor of the kidney are the same disease entity. Molecular and histologic evidence. Am J Surg Pathol. 2009;33:72-80.

M.A. Blanco Parra ${ }^{a, *}$, J.M. Suárez Peñaranda ${ }^{b}$, D.A. Pérez Fentes ${ }^{a}$ y A. Puñal Pereira ${ }^{a}$

aServicio de Urología, Hospital Clínico Universitario de Santiago, Santiago de Compostela, España

bervicio de Anatomía Patológica, Hospital Clínico Universitario de Santiago, Santiago de Compostela, España

*Autor para correspondencia.

Correo electrónico: mico39@hotmail.com (M.A. Blanco Parra). 